\title{
Minimally-invasive coronary artery bypass grafting offers superior outcomes compared to conventional median sternotomy: a propensity-score matched study
}

\author{
Duoduo $\mathrm{Wu}^{1}$, Zhi Xian Ong ${ }^{1}$, Haidong $\mathrm{Luo}^{2}$, GuoHao Chang ${ }^{3}$, Faizus Sazzad ${ }^{4}$, Jai Sule ${ }^{2}$, \\ Peggy $\mathrm{Hu}^{5}$, and Theo Kofidis ${ }^{6}$ \\ ${ }^{1}$ NUS Yong Loo Lin School of Medicine \\ ${ }^{2}$ National University Hospital \\ ${ }^{3}$ National University Health System \\ ${ }^{4}$ National University Heart Centre \\ ${ }^{5}$ National University Heart Centre Singapore \\ ${ }^{6}$ National University Hospital Singapore
}

January 28, 2021

\begin{abstract}
Introduction This study aims to compare the outcomes of minimally invasive coronary artery bypass grafting surgery (MICS $\mathrm{CABG}$ ) versus median sternotomy (MS CABG) within an established minimally invasive cardiac surgical programme in Singapore. Methods We retrospectively analysed 111 propensity-score matched pairs of patients who underwent MICS CABG or MS CABG between January 2009 and February 2020 at the National University Heart Centre, Singapore. Minimally invasive direct coronary artery bypass (MIDCAB) patients were matched to single or double graft MS CABG patients (Group 1) while multivessel MICS patients were matched to MS CABG patients with the corresponding number of grafts (Group 2). Results 111 propensity matched pairs were obtained. The EuroSCORE II in the matched group cohorts were comparable $(\mathrm{p}=0.846)$. In both single and multivessel groups, MICS patients experienced shorter postoperative length of stay $(\mathrm{p}<0.001)$ and lower rates of prolonged ventilation $(\mathrm{p}=0.041)$. Intraoperative transfusion rates and other postoperative outcomes were comparable between MICS and MS patients in the single and multivessel groups.mortality, reintervention heart failure rates were also comparable at 1 year follow up. In Group 1, no significant differences in procedural duration $(\mathrm{p}=0.574)$ and cardiopulmonary bypass duration $(\mathrm{p}=0.699)$ were noted. Moreover, MIDCAB patients had a smaller drop in postoperative haemoglobin levels $(\mathrm{p}<0.001)$. In Group 2, cardiopulmonary bypass $(\mathrm{p}=0.097)$ and length of procedure $(\mathrm{p}<0.001)$ were longer among multivessel MICS patients but did not translate to adverse postoperative events. Conclusion MICS CABG is a safe and effective approach for surgical revascularisation of coronary artery disease.
\end{abstract}

\section{Hosted file}

MICS CABG Manuscript JCS Submission.pdf available at https://authorea.com/users/392204/ articles/506190-minimally-invasive-coronary-artery-bypass-grafting-offers-superioroutcomes-compared-to-conventional-median-sternotomy-a-propensity-score-matched-study

\section{Hosted file}

MICS CABG Tables and Figures JCS Submission.pdf available at https://authorea.com/users/ 392204/articles/506190-minimally-invasive-coronary-artery-bypass-grafting-offerssuperior-outcomes-compared-to-conventional-median-sternotomy-a-propensity-score-matchedstudy 